\title{
PENGURANGAN WASTE DENGAN PENDEKATAN LEAN SIX SIGMA
}

\author{
HANIFUL ATHHAR \\ Departemen Is Operation PT HM Sampoerna Tbk \\ Jl. Bunga Merak 17 Malang \\ E-mail: Haniefulathhar@sampoerna
}

\begin{abstract}
An effective and efficient order fulfillment system is absolutely needed to achieve customer satisfaction. However, wastes which occur in production process would hamper toward its progress, that it is necessary to do an efficiency effort by implementing a concept of Lean Six Sigma which is a combination of lean method and six sigma method. Lean method improves process flow and reduce wastes meanwhile six sigma method improve process capability and reduce variations. In measure phase, known that the most significant waste in production process of sugar at PT. PG. Krebet Baru were waiting, Inventory and Defect.Based on that fact, this research was very necessary to be executed to understand the causes of wastes and to make an improvement plan by using Lean Six sigma approach and Analysis of Ishikawa diagram. From analze phase, it is known that the causes of wastes were (a) The split of job description in inspection session is not focus,(b) The filter in chycling mchinedidn't work well caused by unslilled operators, (c) the number of crushing machine is insufficient so there were material piles. The purposed improvement plans are are (a) Review and improve job description especially in inspection and weighing section, (b) Give additional training to operator who work in spinning section, (c) Machines and tool inspection before starting the production process so it is going to work well.
\end{abstract}

Key words: lean, six sigma, waste, quality, sugar cane, sugar

\section{PENDAHULUAN}

Berkembangnya persaingan pasar di dunia industri manufaktur yang semakin ketat saat ini mendorong beberapa perusahaan manufaktur dalam membuat produk. Perkembangan pasar saat ini menuntut standar kualitas yang tinggi agar tetap dapat berkompetisi di pasar. Permintaan akan kualitas ini tentunya menjadi tantangan bagi produsen agar produknya dapat bersaing dan dapat memenuhi spesifikasi produk sesuai dengan keinginan konsumen. Salah satu hambatan dalam meningkatkan kualitas atau mutu suatu produk adalah biaya. Cara yang kurang tepat dalam meningkatkan kualitas produk dapat menyebabkan naiknya biaya yang pada akhirnya akan dibebankan ke konsumen, dengan menaikkan hargajual produk http://www.army.mil/armybtkc/imdex.htm.

Kepuasan pelanggan erat hubungannya dengan kualitas yang merupakan suatu hal yang sangat penting agar suatu produk atau jasa tetap eksis dalam persaingan. Pertanyaannya adalah apakah cara yang digunakan untuk memenuhi kepuasan pelanggan dan mencapai kualitas sudah tepat atau tidak. Karena dalam proses produksi masih seringkali dijumpai adanya waste yang bisa menghambat pengoptimalan proses produksi. Berbagai macam metode dikembangkan untuk mewujudkan suatu kondisi yang ideal dalam sebuah proses produksi, yaitu tidak adanya waste dalam proses yang terjadi. Oleh karena itu, perlu dilakukan evaluasi terhadap waste dan selanjutnya dilakukan perbaikan.

Beberapa hambatan yang harus dihadapi pada produksi gula mulai dari bahan baku datang sampai produk siap dijual ke konsumen adalah adanya waste yang sering terjadi antara lain defect, waiting dan unnecesarry inventory. Sehingga penerapan kerja yang efektif dan produktif pun terganggu. Dengan demikian maka perusahaan akan melakukan pengurangan waste dengan metode lean six sigma agar hasil produksi memiliki kualitas yang sesuai dengan standar yang berlaku.

\section{METODE}

Data yang dibutuhkan antara lain, jenis waste, critical-to-quality, penyebab waste. Define. Pada 
tahap ini dilakukan beberapa hal yang meliputi: (1) Penggambaran Big Picture Mapping dari proses produksi yang menggambarkan kebutuhan konsumen, aliran fisik, dan aliran material. (2) Identifikasi terhadap permasalahan atau jenis-jenis waste yang terjadi pada proses produksi dengan penyebaran kuisioner identifikasi waste kepada pihak-pihak yang terkait dengan proses produksi.

Measure. Pada tahap ini dilakukan beberapa hal yang meliputi: (1) Identifikasi terhadap waste yang paling berpengaruh terhadap kualitas produk berdasarkan hasil kuesioner dengan bantuan metode Borda. (2) Identifikasi CriticalTo-Quality untuk masing-masing waste yang paling berpengaruh melalui detailed mapping yang ditentukan menggunakan metode VALSAT. (3) Mengukur nilai sigma saat ini untuk mengetahui perlunya dilakukan untuk melakukan perbaikan.

Analyze. Adapun hal-hal yang dilakukan pada tahap analyze ini meliputi: (1) Analisis terhadap waste yang paling berpengaruh. (2) Analisis pengukuran nilai sigma saat ini. (3) Analisis dengan menggunakan Ishikawa diagram untuk mengetahui penyebab waste.

Improve. Pada tahap ini dibuat suatu rancangan perbaikan terhadap faktor-faktor penyebab terjadinya waste untuk mengurangi waste pada proses produksi gula (Gasper, 2003).

\section{HASIL DAN PEMBAHASAN}

Dalam tahap analyze, akan dilakukan analisis terhadap hasil pengolahan data di tahap sebelumnya untuk lebih memahami permasalahan yang ada. Analisis yang akan dilakukan antara lain adalah analisis terhadap waste yang paling berpengaruh, analisis terhadap pengukuran nilai sigma saat ini, dan analisis dengan menggunakan diagram Ishikawa untuk mengetahui penyebab waste.

Berdasarkan hasil pengolahan data kuesioner dan proses brainstorming yang dilakukan bersama dengan pihak manajemen perusahaan, dapat diketahui bahwa waste yang paling sering terjadi dan paling berpengaruh di dalam proses produksi adalah waste jenis waiting, defect dan Inventory (George, Michael, 2003). Waiting memiliki bobot sebesar 0.301369 sedangkan defect memiliki bobot sebesar 0.287671. Hal tersebut dapat dilihat dari hasil pembobotan waste di Tabel 1.

Ketiga waste tersebut, waiting, defects, dan Inventory merupakan jenis kegagalan yang terjadi karena beberapa hal, berdasarkan identifikasi waste dapat ditunjukkan sebagai berikut.

Waiting merupakan keterlambatan suatu proses di dalam proses produksi gula. Berdasarkan hasil identifikasi dalam tahap define, maka dapat dilihat bahwa waiting yang terjadi adalah terlalu lamanya waktu yang dibutuhkan untuk penerimaan dan inspeksi bahan baku pada saat datang sampai pengangkutan kelokasi penggilingan yang memakan waktu lama. Serta penimbangan tebu pada saat tebu datang sampai pemindahan ke dalam lori sebelum sampai kemesin penggilingan. Setelah dilakukan pemetaan proses dengan detailed mapping didapatkan total waktu aktivitas adalah 255.33 jam, seperti yang tersaji pada Tabel 2.

Berdasarkan hasil Process Activity Mapping kita dapat mengetahui bagaimana komposisi aktivitas yang bernilai tambah dan yang tidak dalam proses produksi. Dalam hal ini, semakin banyak Value Adding Acitivity akan semakin baik, dari jumlah total semua aktivitas, 22 aktivitas (43\%) merupakan Value Adding Acitivity,

Tabel 1. Urutan Waste yang Terjadi di Proses Produksi Gula

\begin{tabular}{ll}
\hline \multicolumn{1}{c}{ Jenis Waste } & Bobot \\
\hline Waiting & 0.301369863 \\
Defects & 0.287671233 \\
Inventory & 0.178082192 \\
Tranportation & 0.109589041 \\
innapropriate processing & 0.082191781 \\
Motion & 0.04109589 \\
\hline
\end{tabular}

Sumber: Pengolahan Data

Tabel 2. Kebutuhan Waktu Tipe Aktivitas Proses Produksi Gula

\begin{tabular}{lccccc}
\hline & Operations & Transportations & Inspections & Delays & Storages \\
\hline Waktu (jam) & 3300 & 7680 & 780 & 3000 & 60 \\
Prosentase (\%) & 21.54 & 50.13 & 0.6 & 19.58 & 5 \\
\hline
\end{tabular}

Sumber: Pengolahan Data 
sedangkan 7 aktivitas (12\%) merupakan Non Value Adding Activity, dan 23 aktivitas (45\%) merupakan Necessary but Non Value Adding Activity.

Komposisi terbanyak dari aktivitas proses produksi Gula adalah Necessary but Non Value Adding Activity. Yang artinya diperlukan suatu evaluasi terhadap proses produksi, untuk mengurangi jumlah Necessary but Non Value Adding Activity, dan sebisa mungkin menambah Value Adding Acitivity. Oleh karena itu, evaluasi aktivitas akan ditujukan pada proses Pemeriksaan tebu (quality control). Karena proses inilah yang merupakan Necessary but Non Value Adding Activity tertinggi dan dapat menyebabkan waktu tunggu (waiting) bagi proses selanjutnya.

Defect merupakan jenis pemborosan yang ditandai dengan adanya produk atau material cacat dan tidak sesuai standar. Berdasarkan hasil dari tahap define diketahui bahwa defect yang terjadi dalam proses produksi gula adalah kotoran yang menempel, ukuran kristal, kebocoran sak gula. Ketiga jenis cacat ini merupakan scrap defect yang akan berakibat pada menurunnya kualitas produk dan diperlukannya rework. Dan dengan adanya rework akan menyebabkan penambahan waktu proses yang akhirnya berakibat pada peningkatan biaya produksi. Berdasarkan hasil Quality Filter Mapping, Ketiga jenis Defect inilah yang menjadi Critical to Quality, yang dalam hal ini berarti dengan menurunnya jumlah ketiga jenis defect tersebut akan membawa dampak yang positif baik kualitas proses maupun kualitas produk. Berdasarkan hasil Quality filter mapping juga diketahui bahwa terjadi peningkatan dan fluktuasi jumlah scrap defect di antara bulan Juni hingga November 2007, yang dapat ditunjukan oleh Gambar 1.

Pada Gambar 1 dapat dilihat bahwa tingkat cacat produk melebihi $2 \%$, yang merupakan standar perusahaan. Oleh karena itu, evaluasi dan perbaikan akan berfokus pada pengurangan jumlah kotoran pada kristal, Ukuran kristal dan kebocoran pada sak gula yang terjadi pada proses produksi gula tersebut.

Inventory merupakan jenis pemborosan yang ditandai dengan penyimpanan berlebih atau penumpukan bahan baku yang menunggu diproses, Berdasarkan hasil identifikasi dalam tahap define, maka dapat dilihat bahwa Inventory yang terjadi adalah adaya persediaan, baik material maupun finishing goods yang berlebihan dalam gudang maupun lantai produksi karena menumpuknya bahan baku yang dikirim sekaligus dan menunggu untuk diproses. Setelah dilakukan pemetaan supply chain response matrix didapatkan total day physical stock sebesar 8,66 hari, dan total lead time keseluruhan aktivitas sebesar 12,55 hari dengan perincian Gambar 2.

Berdasarkan Supply Chain Response Matrix (Hines, Piter; Rich, Nick, 2000). Pengawasan dan pengantrian tebu memiliki lead time tertinggi. Perbaikan akan berfokus pada waktu pengawasan dan pengantrian tebu yang mewakili inventory dengan lead time terbesar yang terjadi.

Nilai Sigma akan menunjukkan bagaimana kondisi perusahaan saat ini. Sehingga dapat diketahui apakah dengan adanya waste berakibat pada kinerja proses, dan apakah perlu dilakukan adanya perbaikan (improvement) agar dapat meningkatkan nilai sigma sekaligus mengeliminasi waste. Berikut adalah analisis nilai sigma untuk tiap waste.

Waiting. Perhitungan nilai sigma dilakukan di tahap measure yang didasarkan pada waktu Pemeriksaan dan penimbangan tebu pada saat tebu datang dan terlalu lama sehingga menyebabkan adanya waktu tunggu untuk tebu yang lain,yang memilikitarget dari perusahaan sebesar 6 jam untuk setiap 10 truk tebu. Berdasarkan hasil perhitungan nilai sigma didapatkan sebesar 2.26 dengan yang masih relatif rendah, hal ini berarti terdapat kesempatan sebesar 240000 lori tebu yang waktu pengantriannya melebihi standar (240000 DPMO). Sehingga masih sering terjadi keterlambatan untuk

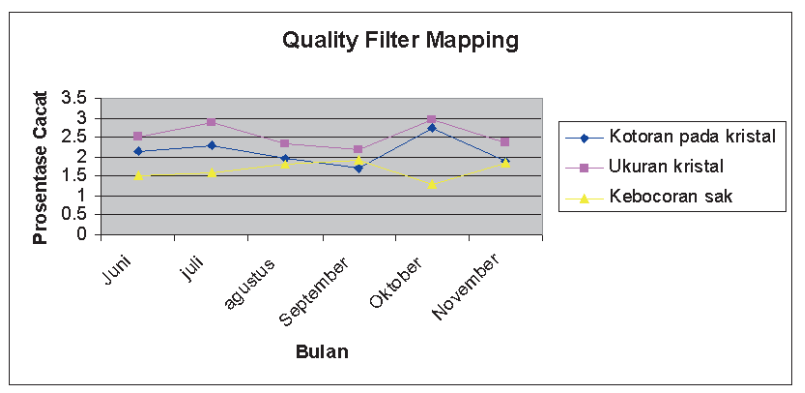

Gambar 1. Diagram jenis cacat pada proses produksi gula 
Cummulative Inventory (Day

Physical Stock) 8.43 days

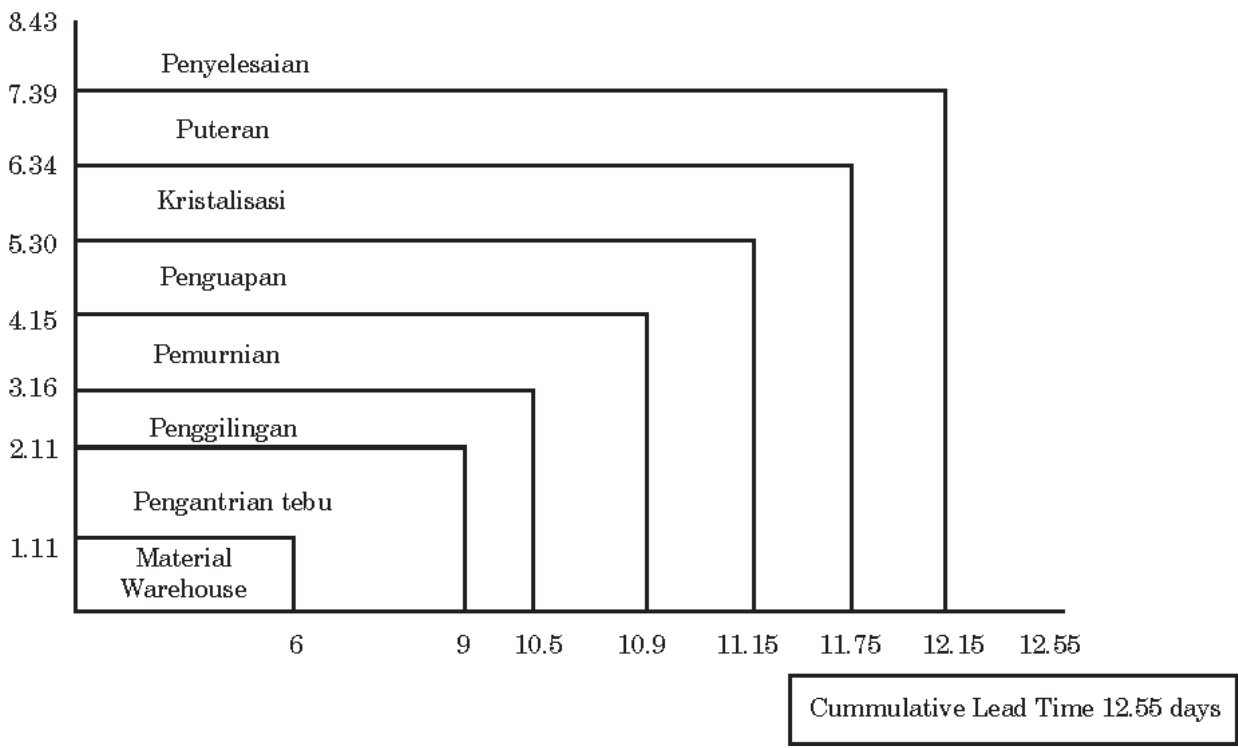

Gambar 2. Supply chain response matrix proses produksi gula

proses selanjutnya yang berakibat pada timbulnya waiting yang merupakan pemborosan yang harus diminimasi. Dengan demikian perlu dilakukan perbaikan oleh perusahaan sehingga nilai sigma dapat ditingkatkan dan proses produksi dapat berjalan lebih lancar.

Defect. Perhitungan nilai sigma dilakukan di tahap measure yang didasarkan pada jumlah scrap defect yang ada di dalam proses produksi Gula adalah Ukuran gula yang terlalu halus atau besar dengan persentase sebesar $2,11 \%$, yang memiliki standar maksimum dari perusahaan sebesar $2 \%$ tiap bulannya. Berdasarkan hasil perhitungan nilai sigma didapatkan sebesar 2.27 yang masih relatif rendah. Sehingga masih terdapat scrap defect yang melebihi toleransi perusahaan. Dengan demikian perlu dilakukan perbaikan sehingga nilai sigma dapat ditingkatkan dan jumlah defect dapat lebih berkurang serta proses produksi dapat berjalan lebih lancar dan hasil produk yang dihasilkan sesuai dengan standar perusahaan.

Inventory. Perhitungan nilai sigma dilakukan di tahap measure yang didasarkan pada jumlah Inventory Bahan baku yang menunggu diproses. Berdasarkan hasil perhitungan nilai sigma didapatkan sebesar 2.39 yang masih relatif rendah, hal ini berarti terdapat kelebihan inventory sebesar 107245 ton tebu (107245 DPMO). Sehingga masih sering terjadi inventory bahan baku yang menyebabkan penumpukan karena menunggu proses produksi yang merupakan pemborosan yang harus diminimasi. Dengan demikian perlu dilakukan perbaikan, sehingga nilai sigma dapat ditingkatkan dan proses produksi dapat berjalan lebih lancar.

Dalam setiap usaha perbaikan kualitas, perlu dilakukan suatu analisis untuk mengevaluasi akar penyebab waste yang paling berpengaruh. Analisis akar penyebab ini akan dilakukan dengan menggunakan diagram Ishikawa (Ishikawa Diagram) (Fryman, Mark A., 2002).

Waiting. Waiting yang terjadi dalam proses produksi Gula di PT PG. Krebet Baru I adalah lamanya waktuyang diperlukan untuk pemeriksaan dan penimbangan tebu oleh kabag tanaman sehingga membuat proses selanjutnya menunggu. Gambar 3 adalah hasil penggambaran diagram Ishikawa dari waiting karena proses pemeriksaan dan penimbangan.

Berdasarkan Gambar 3 dapat diketahui bahwa penyebab waiting karena Pemeriksaan dan penimbangan Tebu adalah dikarenakan empat 
faktor, yaitu metode, manusia, material dan mesin.

Metode. pemeriksaan dan penimbangan tebu dilakukan terhadap keseluruhan truk tebu yang datang diarea pabrik membutuhkan waktu lama karena minimnya operator yang mengakibatkan operator mengerjakan dua pekerjaan, yaitu memeriksa dan menimbang, hal ini disebabkan karena job description yang kurang teratur serta pembagian kerja yang tidak terfokus.

Manusia. Operator diharuskan memeriksa dan menimbang keseluruhan bahan baku. Selain pemeriksaan dan penimbangan dilakukan dengan cara berdiri karena peralatan uji yang ada tidak memungkinkan operator untuk memeriksa memeriksa dan menimbang dengan duduk, atau sikap yang lebih nyaman. Sehingga akan timbul kelelahan yang menyebabkan turunnya konsentrasi dan kinerja operator.

Mesin. Banyaknya tebu yang ditimbang menyebabkan peralatan atau mesin penimbang kelebihan beban, dan juga alat penimbang yang sudah aus karena kurangnya perawatan sehingga akurasi penimbangan menjadi berkurang.
Material. Pengecekan bahan baku yang dilakukan untuk mengantisipasi tebu yang terlalu tua atau muda karena memengaruhi kadar sukrosa dalam tebu yang nantinya akan diambil sarinya saja.

Untuk merencanakan perbaikan dari penyebab waste ini, kita perlu mengetahui apa yang menjadi penyebab utama dari keempat faktor tersebut, yaitu pada faktor material terdapat banyak tebu yang harus diperiksa dan ditimbang. Hal ini membuat mesin menjadi aus karena kelabihan beban. Begitu pula dengan operator yang kinerjanya menjadi berkurang karena faktor kelelahan sehingga terjadi kesalahan dalam membaca indikator alat ukur.

Keempat faktor ini disebabkan karena begitu banyaknya jumlah tebu yang harus diperiksa dan ditimbang, sedangkan operator yang bekerja dibagian ini tidak memiliki pembagian kerja yang cukup baik karena operator harus melakukan pemeriksaan sekaligus penimbangan tebu. Maka dapat disimpulkan bahwa yang menjadi penyebab lamanya waktuyang diperlukan untuk pemeriksaan dan penimbangan tebu adalah karena penentuan job description yang kurang teratur.

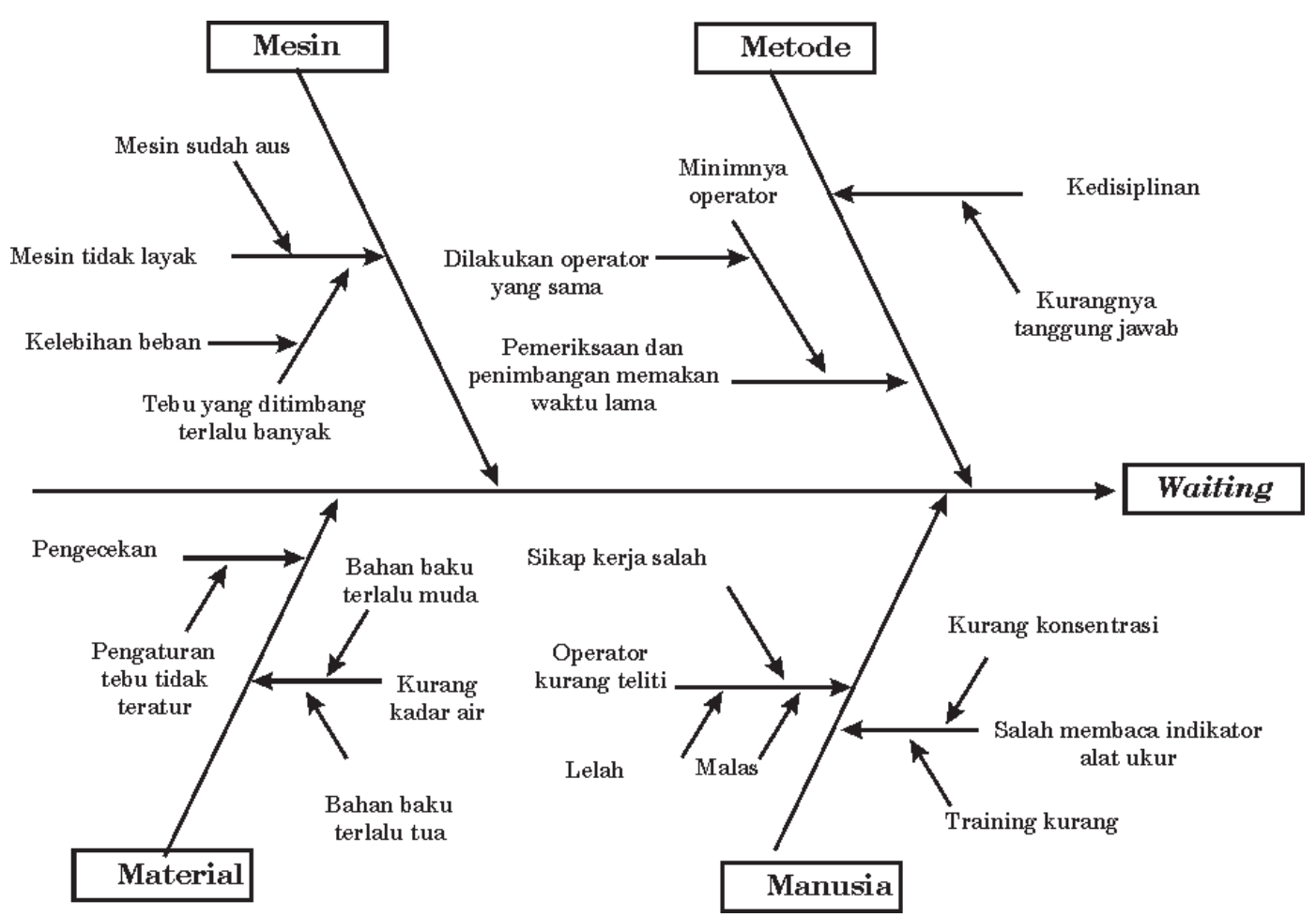

Gambar 3. Diagram Ishikawa untuk waiting 
Defects. Defects terbesar yang terjadi dalam proses produksi gula dimana ukuran gula yang terlalu besar atau terlalu halus. Berikut ini adalah hasil dari penggambaran diagram Ishikawa terhadap penyebab terjadinya cacat pada gula.

Berdasarkan Gambar 4 dapat diketahui bahwa penyebab timbulnya Ukuran gula yang terlalu kecil atau besar adalah disebabkan oleh tiga faktor, yaitu mesin, manusia dan metode.

Mesin. Pada proses penyaringan kristal gula, Saringan 1, 2, 3 pada mesin batch sentrifugal tidak berfungsi baik sehingga proses penyaringan terhalus sampai terkasar menjadi kurang stabil dan continous centrifugal yang selalu bekerja kontinu pada saat pemutaran kristal gula menjadi kurang optimal karena tromoll conis-nya tidak berfungsi dengan baik sehingga hasil gula kurang optimal karena hasil kristal gula kadang terlalu halus atau terlalu besar.

Manusia. Kelalaian operator untuk memeriksa pada saat proses Penyaringan dan pemutaran kristal gula, serta kelalaian operator untuk pada indikator peringatan dan kurangnya ketepatan pengaturan kecepatan mesin.

Metode. Setting peralatan yang kurang lengkap menyebabkan tidak diketahuinya kondisi mesin macet.

Untuk merencanakan perbaikan dari penyebab waste ini, kita perlu mengetahui apa yang menjadi penyebab utama dari ketiga faktor penyebab defect: Ukuran Gula terlalu besar atau terlalu halus adalah karena saringan pada mesin batch sentrifugal tidak dapat bekerja optimal sehingga aliran dari hasil masakan, yaitu kristal gula menjadi tidak sesuai dengan yang diharapkan karena ukuran gula kecil yang akan menjadi gula produksi atau siap kemas tercampur dengan ukuran gula yang terlalu halus. Hal ini disebabkan karena pengaturan saringan yang beropersi secara manual tidak berfungsi dengan baik, dikarenakan terjadi kesalahan operator dalam mengendalikan saringan. Maka dapat disimpulkan bahwa penyebab utama dari

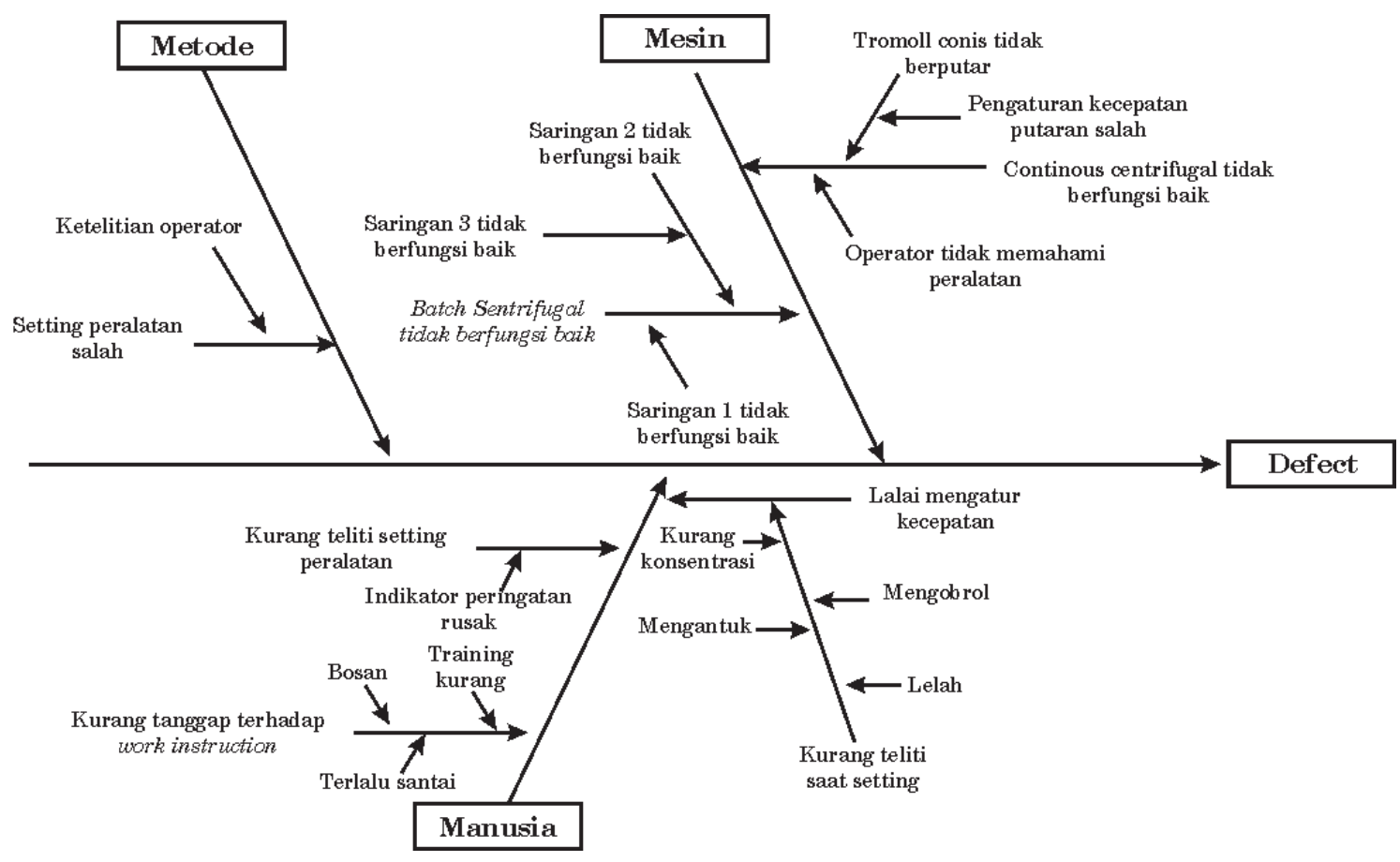

Gambar 4. Ishikawa diagram untuk defect: ukuran gula 
terjadinya defect ukuran gula yang terlalu besar atau halus adalah karena kurang terlatihnya operator.

Inventory. Inventoy terbesar yang terjadi dalam proses produksi gula adalah adanya penumpukan bahan baku yang menunggu diproses. Berikut ini adalah hasil dari penggambaran diagram Ishikawa terhadap penyebab terjadinya Inventory bahan baku (tebu).

Berdasarkan Gambar 5 dapat diketahui bahwa penyebab timbulnya Inventory bahan baku adalah disebabkan oleh empat faktor, yaitu metode, material, mesin, dan manusia.

Metode. Pada saat penerimaan tebu di lokasi penggilingan terjadi banyak kesalahan prosedur dari awal karena waktu bahan baku datang tidak langsung dikirim dan diterima atau ke lokasi penggilingan karena mengantri dan menunggu untuk diproses yang cukup memakan waktu lama dan metode pengaturan bahan baku yang tidak teratur serta kurangnya kedispilnan para operator.
Material. Lamanya waktu menunggu menyebabkan bahan baku yang ada di gudang sementara menumpuk sehingga bahan baku yang tersimpan digudang dapat rusak atau berkurangnya kadar sukrosa pada bahan baku (tebu).

Manusia. Kurangnya skill para karyawan menyebabkan ketidaktauan bahwa penumpukan bahan baku yang terlalu lama dapat mengurangi kadar sukrosa tebu dan kurangnya ketelitian dalam memperhitungkan kriteria bahan baku muda atau tua karena rendahnya tingkat konsentrasi para operator.

Mesin. Banyaknya jumlah bahan baku yang dikirim secara bersamaan dan kurangnya mesin penghancur tebu serta kapasitas mesin dalam menerima bahan baku yang terbatas sehingga menyebabkan waktu pengantrian yang lama sehingga terjadi penumpukan dalam gudang sementara serta terjadinya kemacetan pada mesin yang juga menyebabkan proses terhenti.

Untuk merencanakan perbaikan dari penyebab waste ini, kita perlu mengetahui apa yang menjadi

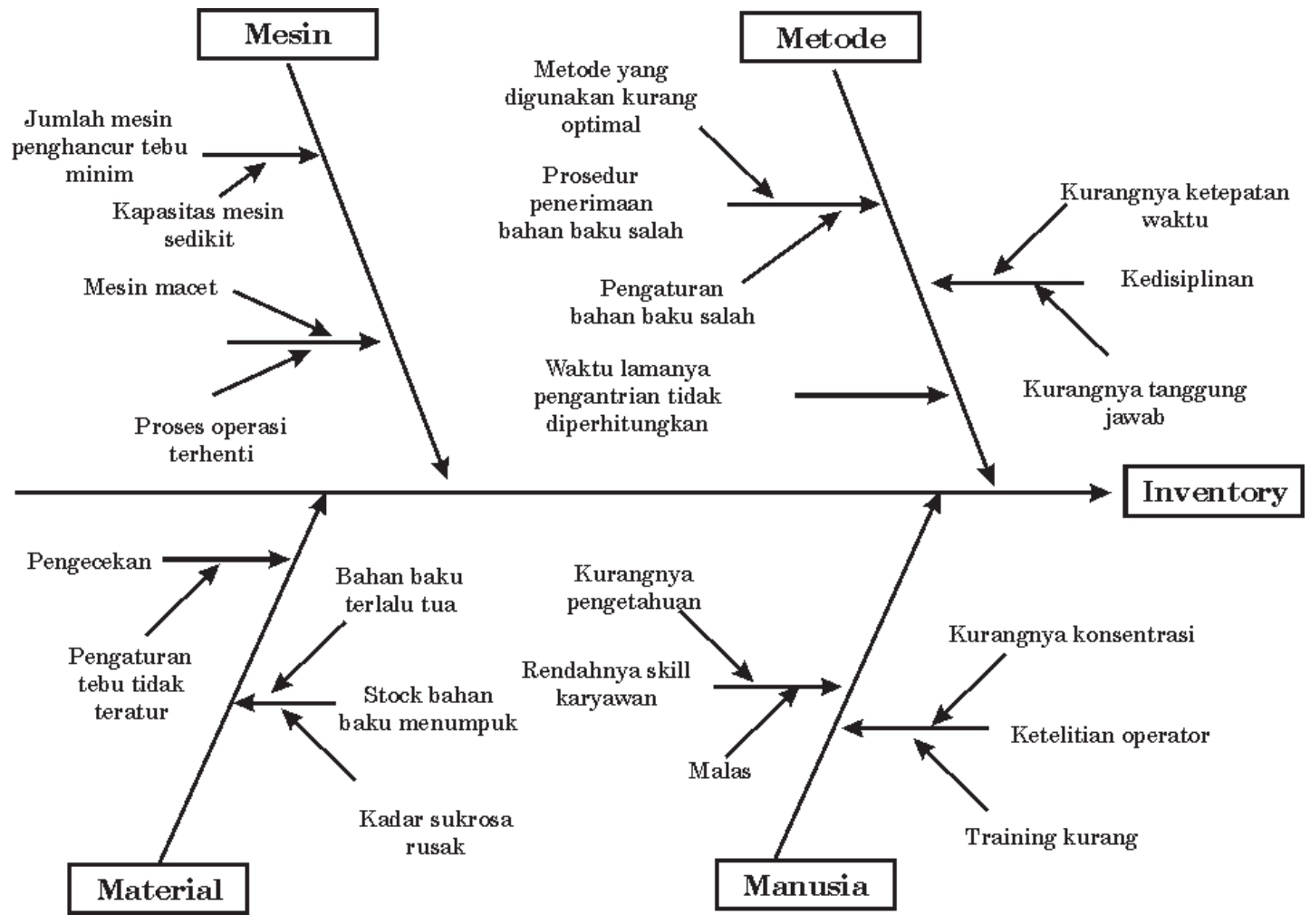

Gambar 5. Ishikawa diagram untuk inventory bahan baku 
penyebab utama dari keempat faktor penyebab terjadinya inventory tersebut adalah kurangnya mesin atau kapasitas mesin dalam menerima bahan baku yang jumlahnya tidak terbatas dan kemacetan mesin yang berakibat proses terhenti dan terjadi pengantrian dan penumpukan bahan baku yang terlalu lama sehingga tebu yang menunggu terlalu lama akan menjadi kering dan hal ini dapat mempengaruhi kadar sukrosa bahan baku.

Improve. Dalam tahap improve, dilakukan perancangan perbaikan proses produksi gula. Sasaran perbaikan dalam tahap ini diarahkan terhadap pengurangan waste yang paling berpengaruh dalam proses pembuatan gula, yaitu waiting, defect dan Inventory.

Rancangan perbaikan untuk meminimasi waiting. Berdasarkan analisis diagram Ishikawa maka rencana tindakan untuk mengurangi adanya waste waiting, defect dan inventory adalah sebagai berikut.

Waste waiting. Dengan adanya penyebab utama waste waiting pada proses pemeriksaan dan penimbangan tebu, yaitu kurang teraturnya pembagian job description karena menyebabkan operator yang bekerja di bagian pemeriksaan juga bekerja di bagian Penimbangan sehingga kinerja operator kurang baik dan tidak terfokus.

Oleh karena itu perlu dilakukan peninjauan dan perbaikan job description secara terpisah sehingga job description untuk operator di bagian pemeriksaan hanya melakukan pemeriksaan tebu, begitu pula di bagian penimbangan hanya melakukan penimbangan tebu sehingga operator dapat mengerjakan pekerjaan lebih teratur dan terfokus.

Waste defect. Dapat diketahui penyebab utama terjadinya defect pada ukuran kristal gula adalah kesalahan proses akibat kurang terlatihnya operator sehingga tidak mengetahui bahwa beberapa komponen mesin yang tidak berfungsi dengan baik, serta pengabaian indikator yang rusak dan tidak segera diperbaiki dan akhirnya memengaruhi pada hasil produksi gula sehingga perlu diadakan training (pelatihan tambahan) kepada para operator khususnya yang mengawasi pada bagian puteran atau pemisahan kristal gula.

Waste inventory. Berdasarkan hasil analisis Ishikawa, diketahui bahwa penyebab utama terjadinya inventory bahan baku adalah kurangnya mesin atau kapasitas mesin dalam menerima bahan baku yang jumlahnya tidak terbatas serta terjadinya kemacetan mesin yang menyebabkan proses terhenti sehingga terjadinya pengantrian dan penumpukan bahan baku yang terlalu lama sehingga memengaruhi kadar sukrosa bahan baku.

Perlu dilakukan pengecekan mesin dan peralatan terlebih dahulu sebelum memulai proses produksi serta menambah jumlah atau kapasitas mesin penghancur tebu sehingga proses dapat berjalan lebih lancar dan mengurangi penumpukan tebu di gudang bahan baku.

\section{SIMPULAN}

Hasil identifikasi waste menunjukkan bahwa waste yang paling berpengaruh dalam proses produksi adalah waiting, defects dan inventory.

Beberapa faktor yang menjadi penyebab timbulnya waste adalah sebagai berikut. Faktor penyebab timbulnya waiting adalah penentuan job description yang kurang teratur pada bagian pemeriksaan dan penimbangan tebu masuk karena banyaknya jumlah tebu yang diperiksa dan ditimbang sehingga menyebabkan waktu menjadi lama. Faktor penyebab timbulnya defect adalah karena saringan pada mesin pemutaran dan saringan gula (batch centrifugal) tidak dapat bekerja optimal, sehingga kristal gula yang dihasilkan kadang terlalu besar atau terlalu halus. Faktor penyebab timbulnya inventory bahan baku adalah kurangnya mesin atau kapasitas mesin yang menyebabkan proses terhenti dan pengantrian serta penumpukan bahan baku yang terlalu lama akan menjadi kering dan dapat memengaruhi kadar sukrosa pada tebu.

Rancangan perbaikan untuk meminimasi adanya waste tersebut adalah sebagai berikut. Rancangan perbaikan yang ditujukan untuk mengeliminasi adanya waiting karena proses pemeriksaan dan penimbangan tebu, yaitu dengan peninjauan dan perbaikan job description untuk operator di bagian pemeriksaan dan penimbangan tebu sehingga pekerjaan dapat lebih berjalan teratur dan terfokus. Rancangan perbaikan yang ditujukan untuk mengeliminasi adanya ukuran gula yang terlalu besar atau halus, yaitu dengan 
memberikan training (pelatihan tambahan) kepada operator khususnya yang mengawasi pada stasiun pemutaran atau pemisahan kristal. Rancangan perbaikan yang ditujukan untuk mengeliminasi adanya inventory bahan baku, yaitu dengan pengecekan mesin dan peralatan sebelum memulai proses produksi serta menambah jumlah atau kapasitas mesin penghancur tebu sehingga proses produksi dapat berjalan lebih lancar dan mengurangi penumpukan bahan baku.

\section{DAFTAR PUSTAKA}

Gasperz, Vincent, 2003. Metode Analisis untuk Peningkatan Kualitas. Jakarta PT. Gramedia Pustaka Utama.

George, Michael L., 2003. Lean six sigma for Service. United States of America. McGraw-Hill.

Himes, Peter; Rich, Nick, 2000. Value Stream Management. Great Britain Prentice Hall.

Fryman, Mark A., 2002. Quality and Process Improvement. United States of America. Delmar.

Deputy Under Secretary of the Army for Business Transformation (DUSA BT), Army Business Transformation Knowladge Center http://www. army.mil/army btkc/index.htm. Download: 4 Maret 2007. 